\title{
Determinants of Successful Everyday Communication of Sailors in International Crews
}

\author{
Tyron 0. M. \\ Senior lecturer in English for professional purposes \\ Kyiv State Maritime Academy named after Sahaydachniy \\ Kyiv, Ukraine
}

\section{Doi:10.5901/jesr.2013.v3n3p209}

\begin{abstract}
The process of globalization can be seen in all spheres of modern life including navigation. So, forming international crews becomes a common practice. It seems to be an urgent issue that seafarers should have skills of adequate international communication, know particulars of culture and everyday life, basics of mentality of seafarers of other nationalities. Question of forming foreign language competence of the future seafarers has been more investigated for the purpose of fulfillment of their professional duties but is being still widely discussed. The question of social everyday communication is not so widely discussed and deeply researched.
\end{abstract}

Keywords: shipboard training, foreign language competence, cultural differences, religious differences, stress and fatigue

According to the international requirements, all members of the crew must be able to establish good relationships between members of the crew on board ship. Life at sea requires not only professional communication but just socializing. To achieve successful everyday communication and efficient fulfillment of their professional duties future seafarers must have a certain level of foreign language competence. The questions of the content of everyday communication and what needs it should ensure arise. It is widely recognized by the maritime industry that human factors including seafarers' psychology problems have contributed to most of maritime accidents. Therefore improving the psychological quality of navigational students has great significance on the enhancement of maritime safety.[1]

The crews the members of which can talk and laugh together and even joke must be working observing safety and enjoying their work despite the mix of different nationalities. Ability to communicate a common language is a crucial factor which ensures the success of multinational crews. The more seafarers understand each other the more efficiently they work. We now realize that issues of intercultural understanding evoke the other complex questions: What kind of communication is needed? How does communication contribute to creating a climate of respect, not just tolerance?

Communication has diverse character. Some researchers investigated linguistic and psychological aspects of communication. When we speak about everyday communication of seafarers it is important to take into consideration research papers on communication in general. It is important to analyze psychological models of interpersonal communication: encorder/decorder model, intentionalist models, perspective-taking models, dialogic models. In dialogic models we speak about collaborative communication.[2]Collaboration in its turn has individual and socio-cultural differences.Cultural adaptation is not an on/off phenomenon. Like many other human abilities, it appears that cultural adaptation develops through stages. With descriptions of the stages of development, interculturalists who are responsible for facilitating cross-cultural encounters are able to diagnose learners' levels of development and thus design their interventions more effectively. A straightforward form of developmental thinking can be illustrated with one of the bestknown of all intercultural concepts: culture shock. [3].There are also some reports on cultural awareness of seafarers.

Modern merchant shipping increasingly utilises a global labour market for seafarers. In recent years this trend has been accompanied by increasing technological innovation at sea including the introduction of direct voice-based communication technologies which have made traditional and universal forms of communication at sea. Thus with the introduction of multilingual crews and the loss of universal forms of communication the importance of English as the 'lingua franca' of the sea has become paramount. To improve standards of English amongst seafarers and to mitigate against accidents and incidents at sea caused by poor communication, a 'top down' approach to language learning has been utilised by industry regulators and training establishments. The effectiveness of 'top down' approaches to language development drawing upon ethnographic research conducted aboard vessels with multilingual crews is obvious. The research proves the importance of communication on board highlighting both job-related and social interaction and communication, and describing how these cannot be considered in isolation. It concludes that with regard to multilingual 
crews the evidence suggests that 'bottom up' learning is more effective aboard than a 'top down' approach. This has implications for seafarers and the shipping industry, but we also accept and support the work of linguists advocating 'immersion' teaching and learning programmes in providing evidence of the ways in which effective learning and communication occur in a 'real' work and social context beyond the confines of a classroom. [4]

Some experiments were carried out in the groups of students of The Kyiv State Maritime Academy. In the empirical way the psychological states of the students during shipboard training in the multinational crews were defined. Then they were predicted the needs in communication in each of the psychological state. They were grouped lexical units to satisfy communication needs in a certain state. Thus it was defined the extant of reasonable and therefore desirable language competence of the future seafarers for everyday communication at sea in a multinational crew.

When interviewers asked seafarers how they handle emotional concerns, answers varied greatly. A significant minority of seafarers cited spiritual belief as helpful for coping with worries, turning to prayer or meditation for relief. Others suggested that fellow crewmates could function as sources of support under certain circumstances. Most seafarers expressed vague concerns about psychological complaints, many felt the "thing men do" is to "be brave." When seafarers were asked if they felt they received adequate "mental preparation" for entering known zones of piracy, almost all respondents said "no" and most of seafarers who encountered the events of piracy were experiencing some clinically significant symptoms afterwards. These symptoms included the following: increased irritability, concern about returning to work, sleep disturbances, increased use of alcohol, deterioration of significant relationships, diminished energy, loss of pleasure in formerly pleasurable activities, thoughts of suicide. At the individual level, seafarers may consider disclosure of emotional suffering a sign of weakness and shame. Ship owners must redouble and sustain current efforts to educate seafarers about symptoms of concern as well as providing means to receive care at sea and at port. Developing company and insurance protocols to intervene before the severity of symptoms increases helps ensure disclosures of mental health issues. Maritime stakeholders have moral and ethical obligations to promote an environment where disclosures about mental and physical health concerns facilitate diagnosis, treatment, and rehabilitation rather than dismissal from employment.

We also may speak about conscious and unconscious mental states of seafarers at sea. In a certain state the seafarer would like to realize this state in words and communication. Some positive states are associated with certain words or phrases that seafarers later will be able to activate through the process of generating these states of mind from the memory of associations. Now we research how to train the students-future seafarers to change their state of mind through changing words and thoughts. These skills will help them to cope with some psychological problems at sea. In a multinational crew the words will be in English, of course, so again we consider this process of activating the state of mind with a foreign language competency.

A person needs communication, whatever state of mind he may be in, joyous or sorrowful.[5]Regardless of the nationality composition of crews, story-telling remains an important part of life aboard and has not been displaced by the sophisticated entertainment and communication systems found on well-equipped ships. Stories are typically told in those passing moments when there are just minute to spare but there is a need to assert some social contact. In their content these stories are not necessarily or even often extensive narratives with elaborate plots punctuated by climaxes and denouements. They just tell of bars visited, beautiful women, lovely ports, sad shipmates, storms and calms, good and bad captains, devious crewing agents, abominable food, and the like[6].Such tales have a long tradition and they unite the work content, work routines and social relationships and create a new professional culture.

The purpose of this part of paper is to describe an empirical study of factors affecting the foreign language competence of students of maritime schools during their shipboard practice on the ships with international crews. Life at sea requires not only professional communication but everyday interaction The question of the importance of foreign language competence has been investigated by foreign and Ukrainian researchers. . The question of the content of everyday communication arises, what needs does it have to ensure?

Research is being also carried out on the basis of the Kyiv State Maritime Academy. Empirical experiment is being now carried out among the students of the second, third and fourth year of study, the Faculty of navigation, departments - "Navigation and Control of Ship" and "Exploitation of Ship Power Plants". Among the students it was surveyed and organized an experimental group of students who had shipboard practice under a foreign flag in international crews. Each member of this group was interviewed. The questions concerned their experience of shipboard training. We tried to find out the difficulties and successes in everyday communication between crew members. We have suggested that the success of foreign language competence is influenced by various mental states which considered to be common for seamen. But we found out that our students being young people, inherent optimism, faith in own strength and success. So students do not mention some mental and emotional states that are characteristic of a sailor. But there were identified 
main problems in everyday foreign language communication, such as differences in cultural customs and traditions, religious differences, stress, fatigue and age differences. Conducting individual interviews allowed to summarize the factors of successful communication in multinational crews. Questionnaire was prepared and a survey was carried out among all students who had had the experience of shipboard training on foreign and mono Ukrainian vessels. Additionally we surveyed:

- $\quad$-Willing to risk (H.Shubert) .20\% of the respondents indicated from -10 to +10 points, the average carefulness .And $80 \%$ - more than 20 points-risk desire. The very profession involves work which put their lives to risk (storms, piracy). But our students are young people who came to the academy on vocation willing to risk and ready for stress, stressful situation are not specified as an important factor forming successful communication due to their romantic perception.

- Determining the need for communication (V.Ryahovskoho) $.60 \%$ of the respondents scored 14-18 Normal sociability. Curious, willing to listen to the interlocutor, patient to communicate, defend their point of view. Go to the contact with strangers. Do not like noisy groups of people.30\% of respondents scored 9-13 points. They are very sociable, fond of expressing own ideas on various issues . Ready to meet new people with a desire . Quick tempered. Lack of patience.10\% over communicative. Take up any cause, although not always bring it to completion. So all the students surveyed had no problems with communication in their native language. But when the survey was conducted concerning communication in international crews, the same students indicated that they did not have sufficient knowledge of foreign language for communication, had reluctance to communicate because of fatigue, showed inability to communicate in a stressful situation and indicated that they preferred to be alone than to communicate.

Summarizing the results of the tests and individual interviews, the students were asked to rank the causes of difficulties in everyday communication on board according to 10 point scale. Some items are similar, which allow the students to focus on these points and to get valid results.

1. I am not very communicative by nature ...................................................................... points

2. I cannot find common topics with senior colleagues ................................................. 5 points

3. Cultural differences hinder me from chat ….................................................................. p points

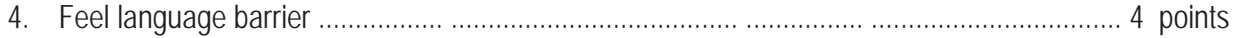

5. Lack of knowledge of foreign language for everyday communication ............................. 7 points

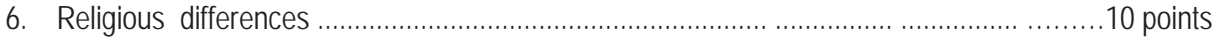

7. No desire to communicate because of fatigue ....................................................... 8 points

8. Stress conditions in certain situations block the ability to communicate successfully ......... 9 points

9. Inability to express their emotions and feelings ......................................................... 2 points

10. I prefer solitude to socializing ..................................................................... 1 point

Thus, it is important that the sailors had adequate international communication skills, knowledge of the culture, ways of life, mentality features of sailors of other nationalities to achieve successful everyday communication and effective performance of duties.

Kahvetsi and Sampson say that the factors underlying the success of the multi-national crew, is to ensure that all have some basic knowledge of general language before they come to serve on board the ship. It will promote social activities, acceptance and conducting anti-racism policies. The question of importance is the ability of captains to deal with people, both beginners or experienced professionals.

On board of one of the studied vessels there were representatives of 14 different nationalities, but this fact did not worsen the differences and helped to smooth these differences. With greater ethnic diversity of the crew the reduce of discrimination and ethnic differences can be found. [7]

\section{References}

Ping Yu; and Huanxin Wang Lecturer, Shanghai Maritime University.

Robert M.Krauss.Social Psychological Models of Interpersonal Communication Columbia University,New York

Bennett, Milton, J. Intercultural communication: A current perspective.1998

Ellis, Neil and Helen Sampson. 2008. The Global Labour Market for Seafarers: Working Aboard Merchant Cargo Ships 2003. June 2008. The Seafarers International Research Centre, Cardiff University.

A.Spirkin. Dialectical Marerialism.Ch.3Consciousness of the World And the World of Consciousness

T.Alderton. The global seafarer: living and working conditions in a globalized industry.Geneva,2004 
ISSN: 2239-978X

E-ISSN: 2240-0524
Journal of Educational and Social Research MCSER Publishing, Rome-Italy
Vol. 3 No. 3

September 2013

"The Formation and Maintenance of Transnational Seafarers Communities" Prof Tony Lane, Dr Erol Kahveci.Dr Helen Sampson Seafarers International Research Centre Cardiff University 